\title{
The influence of community participatory monitoring \& Evaluation on sustainability of saving groups project in Rwanda with reference to savings for transformation(S4T) project in Mbazi Sector of Huye District
}

\author{
Joseph Kirongo Nkunda ${ }^{1}$ and Hesbon O. ANDALA(PhD $)^{2}$ \\ ${ }^{1}$ School of Social Sciences, Mount Kenya University, \\ Kigali, Rwanda
}

\begin{abstract}
Project sustainability is of concern mostly in developing countries. Successful Community participatory M\&E promotes sustainability of development plans, activities, and projects. The researcher conducted this study to determine influence of community participatory monitoring and evaluation on sustainability of Savings for transformation project in Mbazi Sector of Huye District, Rwanda. This study is based on three specific objectives which focuses on how the participation of community on planning stage, implementation stage and M\&E stage Savings for transformation project influence its sustainability. Descriptive design was utilized in the research. The study population was 747 which comprised of 733 project members, 10 community monitors and 4 world vision staff. A sample of 266 was calculated Krjcie \& Morgan Table (1970) for sample size determination. The study adopted stratified, census and random sampling techniques. Primary data was gathered using questionnaires and interview guides, organized, and entered into IBM SPSS version 21.0 for processing and analysis. Both descriptive and inferential findings were presented in tables and graphics. Descriptive results indicated that $97 \%, 90.9 \%$ and $90.6 \%$ of the respondents did agree greatly that participation of community at planning stage, implementation stage and M\&E stage respectively influence sustainability of Savings for Transformation Project. However, 3\%, 9\% and 8.3\% of respondents agreed to a moderate extent. Additionally, the findings indicated high participation of community in most activities of the project. Correlation findings reported a Pearson
\end{abstract}

correlation coefficient of more than 0.8 and significance of 0.000 in all cases indicating high positive association which is significant. The regression coefficients were also positive and significant in all cases indicating a greater positive influence of community participation. The study recommends an enhanced community participatory M\&E to increase sustainability of Savings for Transformation project through engaging all stakeholders in M\&E activities of the project both from planning, implementation, and $M \& E$ stages of the project.

Keywords: Community, Participatory, Monitoring and Evaluation-Project Project Sustainability Savings for transformation groups

\section{Introduction}

Worldwide development projects have participated in enhancing community participatory monitoring and evaluation functions to improve its sustainability outcomes in the last 50 years (Baker, 2011). Due to the growing importance of community participatory monitoring and evaluation underpinning community involvement in project planning, implementation and monitoring decisions made towards their developmental projects all over the world, many projects identified its benefits and they are trying to establish operations that promote project sustainability (Roger and Tim, 2008).

Most people reside in rural areas in developing countries with little access to financial services (Ksolla et al., 2016). Hence, formation of savings groups that facilitate access to savings and loans to support the local farmers that face financial 
constraints before harvesting crops. Farmers have limited access to financial resources due to several barriers ranging from information asymmetry, high interest rates, less collateral among others. Thus, saving groups project applies banking methodology to offer loans to rural communities, the opportunities to purchase shares and lend themselves with agreed interest rate on group basis (Ksolla et al., 2016).

Community Participatory Monitoring and Evaluation among savings groups were employed in countries in the region of Mekong such as Cambodia, Laos, Myanmar, and Viet man for years in empowering Cambodian women to assess financial support for better education (CARE Australia, 2016). Financial empowerment, group member training was the primary business of savings groups for the poor people who work together, receive their saving shares and investment for their own businesses which generates income for their families (USAID, 2014).

Through participatory monitoring and evaluation, the community gets empowered economically, develops a feeling of involvement in decision making, education and dietary improvement and sense of selfrealization and better home relationship. (USAID, 2014). In addition, these outcomes of community participatory monitoring and evaluation of savings groups are always associated with positive effects such as maintaining better financial records, plans readjustment to enhance the achievement of goals and objective of the project, providing better stakeholder feedback that increase community participation and support in planning, implementation and monitoring of project activities.

Savings groups were in existence for over 25 years serving the poor famers and women in rural areas to enable them to become financially empowered, have resource control hence exploit income generating opportunities. By 2009, CARE International had supported 6,699,257 saving groups' members in 317,335 groups in 46 countries whereby $59 \%$, $17 \%, 13 \%, 10 \%$ and $1 \%$ were distributed in Eastern, Western, Southern Africa, Asia and Latin America respectively (CARE international, 2017 report).

The same report of Care international (2017 report) showed that CARE had indeed linked over 1300000 members to various formal financial institutions. Those groups include: 16,035 groups in Tanzania, 15,741 in Rwanda, 6,752 in Kenya, 4,907 in Uganda, 4,469 in India, 2,592 in Malawi, 1,268 in Ghana, 844 in Mali, 801 in Cote d'Ivoire, 62 in Burundi, 36 in Haiti, 27 in Somalia \& Somaliland, 25 in Myanmar, and 6 in Vietnam (CARE International, 2017).

In the region, Tanzania has been said to have implemented the Village Saving and Loan Associations program successfully with well aligned
Monitoring and Evaluation. For instance, 2015 CARE International report in Tanzania indicated $78 \%$ and $55 \%$ of women and men depended on Village Savings and Loans Associations for life improvement

TIR (2016) stated that proper Monitoring and Evaluation of this Village Savings and Loans Association program in Tanzania has led to increased community participation, which has resulted to increase in returns, enhanced knowledge among others. According to Karlan et al (2015), good Monitoring and Evaluation in the Village Savings and Loans Association programme in Tabora enhanced accountability which attracted other organizations like Agha Khan and AFDB to join for support.

In Rwanda, World Vision participated in promoting Savings for Transformation (S4T) mod whereby in 2018, it has supported $1,500 \mathrm{~S} 4 \mathrm{~T}$ that have over 35,000 members in which $80 \%$ of them were female. The same reports indicate that Huye District had over 13, 028 people in 484 S4T (World Vision, 2018 report). Different empirical literatures in the related fields have indicated that voluntary savings and loans associations influence sustainability of small and medium enterprises based in Kayonza District of Rwanda (Sibomana and Shukla, 2016).

Other empirical literatures of the studies conducted in related field on savings and loans association and economic conditions of pro-poor people by Mbonimpa (2016) have revealed that saving and loans associations have a positive effect on socioeconomic conditions of pro-poor people in rural areas of Busanza sector in Nyanza District, Rwanda. Another study of Niyirera and Mulyundi (2018) has revealed that savings groups have made a great contribution on building sustainability of rural livelihood of Rwanda. Thus, it is well observed that community participatory monitoring and evaluation dignified in terms of community participation in planning, implementation and monitoring was given less attention by several studies conducted in regard to sustainability of savings groups.

\section{Review of Literature 2.1Community Participatory M\&E}

Estrella and Gaventa (1998) described Participatory $\mathrm{M} \& \mathrm{E}$ as a process by programs and stakeholders to track progress and shed light to them (both stakeholders and program managers) on the state of meeting project objectives and resource use, inform program implementation and decision making.

Negotiation involves accepting different views and embracing disagreements and conflicts in the process 
of evaluation which focuses on its objectives, methodology and resulting actions.

Monitoring and evaluation is the basis for changing project interventions and assessment of quality of project activities. (Jackson and Cecile, 1997). Monitoring and evaluation is the only tool for measuring the impact of project activities.it aids managers and policy makers in making informed decisions on programme operations. In addition, it helps in optimal use of available resources. (Kelly and Magongo 2007). M\&E also provides data which is used in making strategic plans, project designing and implementation and in resource allocation and reallocation. (Hatry and Lampkin, 2009).

Monitoring involves continuous data collection during project implementation for ascertaining the project progress towards achievement of its objectives. The tools of data collection in this case are often included in project activities for continuous flow. According to Kusek \& Risk (2004) monitoring takes dimensions like process, technical, assumption, impact and financial. Magigi (2014) stated that M\&E forms one pf the key management functions in project management in both developed and developing countries and has increasing become common practice overtime. This is due to its key role in ensuring positive outcomes in projects hence societal growth.

Technical monitoring entails measuring the strategy adopted in project implementation against the set goals to ascertain its relevance. It mostly dwells on the activities conducted. For example, in case of safe water project, technical monitoring will involve putting a strategy to ensure enough uptake water chlorination by women. Minimal uptake might result from time constraint such that women cannot make it to dispensers. Therefore, household distribution bottled chlorine could be the remedy to be adopted. (Kuesk \& Risk, 2004)

Mayne, et al.., (1997) explains that there has been a shift from the traditional M\&E to modern M\&E which is based on performance by governments and development partners. The traditional M\& E however is more focused on project inputs activities and outputs. The project log frame outlines the assumptions underlying the working of any project and they play a role in determining the performance of a project though they are out of control of the project. Assumption monitoring therefore involves measuring these external factors to monitor their effect on project performance. (Kuesk \& Risk, 2004)

According to Bamberger (2009), community Participatory monitoring greatly contributes to successful analysis and interpretation of results since the beneficiaries are key stakeholders and forms the main target of the project. However, the engagement

\section{ISSN 2455-6378}

of beneficiaries should be controlled since too much and too low engagement have negative impact on evaluation process. (Patton, 2008).

There are various benefits of engaging all stakeholders in project decisions which include relevance of findings, improves stakeholders' sense of ownership, increases stakeholder understanding among others. Financial monitoring involves comparing what has been spent in the project and the intended or budgeted amount to ascertain deviations. Financial monitoring is very essential to avoid wastage of finances and in enhancing accountability and efficiency in production. (Kuesk \& Risk, 2004).

Impact monitoring on the other hand concentrates on assessment of project impact on the intended persons. Project impacts are always measured after long period of time to ascertain an improvement in life conditions of beneficiaries. Impact monitoring is always conducted with guidance of specific impact indicators. Stakeholders are key players in the success of the project and therefore their involvement unpacks different perspectives which can be assessed to arrive at a common ground.

Overtime, projects have focused on addressing social problems which are majorly faced by community members and therefore their involvement is key. Through involving the community in M\&E process, project implementers are able to get relevant information from the past and ongoing activities which can be used for planning purposes. Lack of Community Participatory M\&E may raise uncertainty in the direction the project is taking, the project progress and future efforts needed to be improved. (UNDP, 2002). The sole purpose of Community Participatory monitoring and evaluation to assess and measure performance for effective delivery of project outcomes.it encompasses closely linked project management functions hence at times complicated to incorporate on projects. (Crawford and Bryce, 2003) Community Participatory M\&E complements but there is always slight distinction (Passia, 2004).

As a tool of observing and recording project activities, Monitoring involves a process of gathering relevant information in a project and reporting the progress feedback to the donors for the purpose of decision making and improving the outcome. (Bartle 2010). Additionally, monitoring involves stakeholders getting regular feedbacks on the progress of project activities geared to the achievement of goals (UNDP, 2009). Evaluation on the other hand entails assessing the ongoing or competed projects to determine the significance and realize objectives. Through this, efficiency and effectiveness on project activities and processes is assured. (Kusek \& Risk, 2004). 


\subsubsection{Sustainability of Savings Groups project}

Development of long-term strategies is the only way through which sustainability can be achieved. The strategy consolidates both physical, economic and social factors. (Hamdy, 1993). Total Sustainability demands improving the lives of community in all the above-mentioned dimensions both in the current state and future. (Jesse, 2008). Therefore, it must ensure that the activities undertaken are sound ecologically, socially and economically now and in the future. Brent and Erick (2005) also stresses the inclusion of all factors in all dimensions to achieve sustainability objectives. Therefore, a sustainable project should focus on both present and future generations needs.

Social sustainability advocates for fairness in resource distribution in providing social services so that everyone in the society is able to feel the impact of the social service like education, health, gender among others. Harris and Goodwin (2001). It focuses on enhancing local empowerment through encouraging social interaction and sense of communism among the people. (Putnam, 2000).

While pointing out sustainability challenges, (Gareis, et al., 2009) gave much focus on project contents and their results for example climate change, public health and clean energy and overlooking the management side. However, the contrasting view on this incorporated in addition the values and ethics, accountability, and risk limitation strategies as very essential in project sustainability. (Labschagne \& Brent, 2004). This study looks at sustainability in the context of people being able to continue the project to the future using their own resources so that the future generation also benefits.

In the context of business, the main driver of sustainability is the self-interest towards profitability and shareholder value (Harjoto, et al., 2014). Better sustainability attracts more resources to the firm hence market opportunities increases in addition to more employees. (Fombrun, Gardberg, \& Barnett, 2000). Stakeholder relations management is this very important and contributes to competitive advantage. (Barnett \& Salomon, 2006; Porter \& van der Linde, 1995).

Monitoring and Evaluation facilitates sound decision making by tracking the project progress. (Sera and Beaudry, 2007). UNDP (2002) perceives monitoring as a continuous process whose role is to provide an indication to the management on the progress of project. On the other hand, Shapiro (2002) opines that monitoring involves continuous information gathering and analysis as the project progresses. IFRCRCS (2011) also perceives monitoring as continuous information gathering and analysis to enable measurement of progress compared with laid down target.

Evaluation on other side involves assessment of a project activities either ongoing or completed in order to ascertain the achievement of objectives, sustainability, and efficiency. (IFRCRCS, 2011). Therefore, Evaluation deals with comparing actual project impacts against the agreed plans. Evaluation can be formative focusing on the ongoing project for improvement or summative conducted at the end of the project life cycle to draw conclusions from the completed project. (Shapiro, 2002). Lefevre et al., (2000), project evaluation enables the stakeholders to contribute sound decisions that will steer the project towards success not just impact assessment.

Philip et al., (2008) asserts that Participatory M\&E involves engagement of all stakeholders in all stages of project in monitoring and evaluating project activities, controlling and coming up with corrective mechanisms. Primary stakeholders are the main focus of participatory M\&E (World Bank, 2010a). The M\&E terms of reference is built by all stakeholders including community representatives. The study found that participatory M\&E promotes commitment and ownership by the locals to the project both before and after completion. (Barasa and Jelagat, 2013).

World Bank report of 2010 brings out the importance of community participation in $\mathrm{M} \& \mathrm{E}$ on project sustainability. The various importance includes the chance to offer new inclusive ways of learning from change that responds to the needs of the vulnerable. In addition, participatory $\mathrm{M} \& \mathrm{E}$ also contributes to measurement of project effectiveness and beneficiary empowerment hence achievement of project goals. There is also room to offer corrective action in case the M\&E outcome necessitates the same in a bid to improve performance. (ALNAP, 2009).

\section{Materials and Methods}

A descriptive research design with a mixed method that approves the inclusion of qualitative and quantitative facts that are conducive to constructing a broader view of the study was adopted. It facilitated the capturing of various perspectives, statistical analysis, and summary of findings to add more value to the work and make it more representative. Inferential statistics was used to show the relationship and influence of community participatory $M \& E$ on project sustainability.

Kombo and Tromp (2006) describe study population as team of objects and or individuals where sample is drawn for successive measurement. According to World Vision (2020) report on the updated number savings for transformation project, the number of community members participating in S4T project in Mbazi sector stood at 747 . The study therefore was 
conducted in Mbazi Sector of Huye District with the target population of the $29 \mathrm{~S} 4 \mathrm{~T}$ that have 733 members, 10 community monitors and 4 staff of world vision to make it 747 in Mbazi Sector of the Huye District.

This populace focused on one event convenient to the researcher, time handy for search, and load range limitations.

Kombo and Tromp (2011) delimit a populace as a crew of individuals, objects, or devices that are proven to measure. The target population was 747 out of 29 S4Ts in the Mbazi sector consisting of 733 S4Tmembers, 10 community agents and 4 staff of

Table 3 1:Stratification of Sample Size savings for transformation project. The researcher utilized Krejcie and Morgan (1970) table to determine sample size.

Since the population was heterogeneous, the sampling techniques used were stratified random sampling and census method. Hence, this required a need of applying simple random while selecting 266 respondents from 747 target population where 252 members of Savings for Transformation project, census while taking the 10 whole number of community agents and4 staffs of saving for transformation project as the relevant employee of World vision who are in charge of the project in Huye District.

\begin{tabular}{llll}
\hline Respondents & Target population & Sample size & Sampling Technique \\
\hline Members of S4T Project & 733 & 252 & Simple random \\
Community agents / monitors & 10 & 10 & Census \\
S4T project staff/ WV & 4 & 4 & Census \\
Total & $\mathbf{7 4 7}$ & $\mathbf{2 6 6}$ & \\
\hline
\end{tabular}

Source: World Vision, 2020

A questionnaire is also an instrument of data collection. It involves open and closed questions or statements to which the respondents must react. Further, close-ended questions are a list of questions providing a set of fixed alternatives from which the respondents must choose a reply. On the other hand, open-ended questions are questions permitting the respondents to answer as they see and encourage free and lengthy discussion. Hence, the researcher used both open and close-ended questions for the purposes of efficiency in data collection. The questionnaire was appropriate in gathering adequate primary data for the study through administering both open and closed ended questions.

Interview as data-collection technique involves oral questions between the researcher and respondents, either individually or as a group. In this study, the researcher conducted the interview especially with 10 community agents of S4T groups and 4 staff of WV who had first-hand information. Thus, different questions were asked in different forms and helped researcher to obtain good quality data.

The researcher used interview guide to collect need qualitative information form the project staff about the influence of community participatory M\&E on sustainability of S4T project in Mbazi Sector of Huye District.

Document analysis involves the file analysis. These files include written materials that consist of statistics associated with the research.In this research, official textbooks, files and revisions have been used to search as far as viable for sources to acquire archives on the subject being studied. In the case of S4T, annual reports, motion plans, and other first-rate archives related to the subject matter have been consulted for records that the researcher can also want to no longer acquire through the interview schedule.

This involves data coding, data collection, data entry, and database editing and data base export from Census and Survey Processing System (Cspro version7.4) to IBM SPSS (version 21.). Then, this data was processed and produced in form of frequency and mean tables in relation to Likert scale data analysis, Pearson correlation tables and regression tables to indicate both correlation and regression between the variables of the study.

\section{Results and Discussion}

4.1. Demographic characteristics of Respondents This sectionfocuses on gender, age and education of respondents which help to analyze, present, and interpret the research findings.

Table 4.1:Gender of respondents

\begin{tabular}{lll}
\hline & Frequency & Percent \\
\hline Male & 59 & 22.2 \\
Female & 207 & 77.8 \\
Total & 266 & 100.0 \\
\hline
\end{tabular}

Source: Primary Data, 2020

The results in Table 4.1 indicate that $77.8 \%$ of respondents who participated in this study are female while $22.2 \%$ are male. This means that saving for transformation project is gender sensitive since both male and female participate in M\&E activities. On 
the other hands $77.8 \%$ of female who participate in the Savings Groups, this show that female predominance is caused by the fact that many projects through which most Savings Groups were formed targeted females' financial inclusion.

Table 4. 1:Age of respondents

\begin{tabular}{lll}
\hline & $\begin{array}{l}\text { Frequ } \\
\text { ency }\end{array}$ & Percent \\
\hline 18-25 Years & 37 & 14.0 \\
26-35 Years & 72 & 27.1 \\
36-45 Years & 103 & 38.7 \\
46-55 Years & 40 & 15.0 \\
\hline
\end{tabular}

ISSN 2455-6378

\begin{tabular}{lll}
$56-65$ Years & 14 & 5.3 \\
Total & 266 & 100.0 \\
\hline
\end{tabular}

Source: Primary Data, 2020

The results in Table 4.2 indicate that $38.7 \%$ of respondents who participated in this study are 36-45 years old, $27.1 \%$ are 26-35 years old, $15.0 \%$ are 4655 years old, $13.0 \%$ are $18-25$ years old and lastly $5.3 \%$ are within $56-65$ years old. This implies that a big number of stakeholders in the Savings for transformation project are in the youthful age bracket of 36-45 years old and are still energetic to contribute to the sustainability of the project.

Table 4. 2:Education Level of Respondents

\begin{tabular}{lll}
\hline & Frequency & Percent \\
\hline Never attended school & 23 & 8.6 \\
Primary not completed & 22 & 8.3 \\
Primary completed & 52 & 19.5 \\
Secondary not completed & 100 & 37.6 \\
Secondary completed & 65 & 24.4 \\
Postgraduate & 4 & 1.5 \\
Total & 266 & 100.0 \\
\hline
\end{tabular}

Source: Primary Data, 2020

The results in Table 4.3 indicate that $37.6 \%$ of respondents who participated in this study did not complete secondary education while $24.4 \%$ completed. The table also show that $19.5 \%$ of respondents completed primary education excluding those who proceeded to higher levels while $8.3 \%$ never completed. Lastly the table indicate that $8.6 \%$ of respondents never attended school while $1.5 \%$ had postgraduate qualification. This implies that a greater percentage of Savings for transformation stakeholders are educated and can fully understand the importance of community participatory $\mathrm{M} \% \mathrm{E}$ on project sustainability.

years' experience while $18.8 \%$ have 4 years' experience. Additionally, $7.1 \%, 6.4 \%$ and $1.5 \%$ of respondents have 1 year, less than a year and 5 years and above experience at S4T project respectively. Thus, it implies that a big number of respondents who participated in this study have spent between 2 years to 4 years in their groups of S4T project in Mbazi Sector, Rwanda.

4.2. Influence of Community Participation in Monitoring and Evaluation on Sustainably of Community Based Projects

Lastly researcher sought respondents' opinion on the state of implementation of the project M\&E activities at the savings for transformation project. The findings in the table 4.4 in appendix 1 indicate that majority of respondents accounting for over $90 \%$ did indicate they agree that various monitoring and evaluation activities are implemented in the project. Community participation in $M \& E$ of savings for transformation project and project sustainability.

This was assessed by seeking respondents' opinion on the extent to which community participation in M\&E influences the sustainability of savings for transformation project. The findings are shown in the following table 4.13 .

Table 4. 4: Participation of MBAZI community in monitoring and evaluation of savings for transformation project influence sustainability of the project

\begin{tabular}{lllll}
\hline & Frequency & Percent & Weighted Mean & SD \\
\hline Very Great Extent & 91 & 34.2 & 1.76 & .645 \\
Great Extent & 150 & 56.4 & & \\
Moderate Extent & 22 & 8.3 & & \\
Little Extent & 3 & 1.1 & & \\
Total & 266 & 100.0 & & \\
\hline
\end{tabular}

Source: Primary Data, 2020 
The above table 4.4 shows Likert Scale data (1-very great extent, 2-Great extent,3-Moderate extent, 4litte extent, 5- not sure) with [mean $=1.76$ and $\mathrm{SD}=.645]$ and $56.4 \%$ and $34.2 \%$ of respondents were in agreement that community participation in monitoring and evaluation influences sustainability of savings for transformation project to great extent and very great extent respectively. Additionally, $8.3 \%$ and $1.1 \%$ of respondents opined that community participation in M\&E influences project sustainability to a moderate extent and little extent respectively. Thus, it implies that community participation in $M \& E$ influences sustainability of $\mathrm{S} 4 \mathrm{~T}$ project in Mbazi Sector, Rwanda. Moreover, in an interview with community Agents in Mbazi sector, they stated that they have local peer network

Table 4. 5: Correlation analysis between community participatory M\&E and Sustainability of savings for transformation project in Mbazi Sector, Rwanda organizations that ensures delivery of needed capacity without project support. They added that their involvement in project activities have made them to be more sustainable so that they are able to endeavor even if the donors cease out their funds. One of them stated that: "Ihave been in this project have started with S4T project, we have only received capacity building training and seminars because all the funds we have today are our own contributions. I am happy world vision has involved us since the design of this project because we started with our own funds. This assures me that even after phasing out their supports that they are giving us we will continue." (Primary Data, 2020). as a beneficiary for a long term period because I

\begin{tabular}{|c|c|c|c|c|}
\hline & & $\begin{array}{l}\text { continuous } \\
\text { promoting } \\
\text { and } \\
\text { mobilization } \\
\text { S4T project }\end{array}$ & $\begin{array}{l}\text { continuous } \\
\text { training of } \\
\mathrm{S} 4 \mathrm{~T} \text { project }\end{array}$ & $\begin{array}{l}\text { continuous } \\
\text { saving and } \\
\text { borrowing } \\
\text { without } \\
\text { external } \\
\text { support }\end{array}$ \\
\hline \multirow{3}{*}{$\begin{array}{l}\text { Community Participation in planning } \\
\text { process }\end{array}$} & Pearson Correlation & $.899^{* * *}$ & $.909^{\text {*** }}$ & $.892^{* * *}$ \\
\hline & Sig. (2-tailed) & .000 & .000 & .000 \\
\hline & $\mathrm{N}$ & 266 & 266 & 266 \\
\hline \multirow{3}{*}{$\begin{array}{l}\text { Community Participation } \\
\text { implementation process }\end{array}$} & Pearson Correlation & $.870^{* *}$ & $.881^{* *}$ & $.862^{* *}$ \\
\hline & Sig. (2-tailed) & .000 & .000 & .000 \\
\hline & $\mathrm{N}$ & 266 & 266 & 266 \\
\hline \multirow{3}{*}{$\begin{array}{l}\text { Community Participation in project } \\
\text { monitoring and evaluation }\end{array}$} & Pearson Correlation & $.826^{* *}$ & $.837^{* *}$ & $.816^{* *}$ \\
\hline & Sig. (2-tailed) & .000 & .000 & .000 \\
\hline & $\mathrm{N}$ & 266 & 266 & 266 \\
\hline
\end{tabular}

Source: Primary Data, 2020

The findings from the above Table 4.5 indicate that the Pearson correlation coefficient for community participation in planning process and continuous promotion and mobilization, continuous training and continuous saving and borrowing without external support are 0.899, 0.909 and 0.892 respectively. secondly the Pearson correlation coefficient for Community participation in implementation process and continuous promotion and mobilization, continuous training and continuous saving and borrowing without external support are $0.870,0.881$

Table 4.6: Model Summary of Community Participatory M\&E and Continuous saving and borrowing without external support as indictors of project sustainability in Mbazi Sector, Rwanda

\begin{tabular}{llll}
\hline Model & R Square & Adjusted R Square & Std. Error of the Estimate \\
\hline 1 & .821 & .819 & .24883 \\
\hline
\end{tabular}

Source: Primary Data, 2020

The results in Table 4.6 indicate $\mathrm{R}$ Square value of 0.821 . This implies that community participation in project planning, implementation and monitoring and and 0.862 respectively. lastly the Pearson correlation coefficient for community participation in project monitoring and evaluation and continuous promotion and mobilization, continuous training and continuous saving and borrowing without external support are $0.826,0.837$ and 0.816 respectively in all the cases the significant value is 0.000 . These results indicate that there is strong positive association between community participatory M\&E activities and project sustainability.

evaluation jointly accounts for $82.1 \%$ variations in continuous saving and borrowing without external support. 
Table 4.7: Analysis of Variance (ANOVA) of Community Participatory M\&E and Continuous saving and borrowing without external support as indictors of project sustainability in Mbazi Sector, Rwanda

\begin{tabular}{llllll}
\hline Model & Sum of Squares & Df & Mean Square & F & Sig. \\
\hline Regression & 74.429 & 3 & 24.810 & 400.707 & $.000^{\text {b }}$ \\
Residual & 16.222 & 262 & .062 & & \\
Total & 90.650 & 265 & & & \\
\hline
\end{tabular}

a. Dependent Variable: Continuous saving and borrowing without external support

b. Predictors: (Constant), community participation in project planning, community participation in project implementation, community participation in project $\mathrm{M} \& \mathrm{E}$

Source: Primary Data, 2020

The findings in Table 4.7 indicate calculated $\mathrm{F}$ statistic value of 400.707 and significance value of 0.000. This is an indication that the linear model

participatory M\&E on continuous saving and borrowing without external support is appropriate. used to predict the influence of community

Table 4. 8: Coefficients of Community Participatory M\&E and Continuous saving and borrowing without external support as indictors of project sustainability in Mbazi Sector, Rwanda

\begin{tabular}{lllllll}
\hline Model & \multicolumn{2}{l}{$\begin{array}{l}\text { Unstandardized } \\
\text { Coefficients }\end{array}$} & \multicolumn{2}{l}{$\begin{array}{l}\text { Standardized } \\
\text { Coefficients }\end{array}$} & & S \\
\cline { 2 - 5 } & B & \multicolumn{2}{l}{ Std. Error } & Beta & & \\
\hline (Constant) & .094 & .047 & & 1.999 & .047 \\
CP in project M\&E & .525 & .063 & .534 & 8.319 & .000 \\
CP in project implementation & .258 & .063 & .257 & 4.112 & .000 \\
CP in project planning & .155 & .053 & .152 & 2.952 & .003 \\
\hline
\end{tabular}

a. Dependent Variable: Continuous saving and borrowing without external support

\section{Source: Primary Data, 2020}

The results in Table 4.8 above indicate that predictors of community participatory $\mathrm{M} \& \mathrm{E}$ have positive coefficients and significance values less than 0.05 thus enhance positive significant influence on Continuous saving and borrowing without external support in savings for transformation project. Therefore, the linear model become $\mathrm{Y}=.094+.525 \mathrm{x}_{1}+.258 \mathrm{x}_{2}+.155 \mathrm{x}_{3}$. the model indicates that $1 \%$ change in community participation in planning, implementation, and M\&E leads to $52.5 \%$, $25.8 \%$ and $15.5 \%$ proportionate change in continuous saving and borrowing without external support respectively. This regression equation indicates that there is a positive significant influence of predictors of participatory M\&E on Continuous saving and borrowing without external support of savings for transformation project.

\section{Conclusions}

From the findings above the researcher came up with some conclusions.

First, the study concludes that community members participated in the savings for transformationproject activities from planning, implementation and monitoring and evaluation stages of the project though not a very great extent. Additionally, savings for transformation project implemented the various activities in the three stages successfully as supported by large percentage of respondents.
Secondly, there is a significant high positive association between each of the community participatory $M \& E$ activities including participation in project planning, implementation and $\mathrm{M} \& \mathrm{E}$ and each of the project sustainability indicators including continuous promotion and mobilization of savings for transformationgroups, continuous training within groups and continuous saving and borrowing without external support. Hence there is strong positive association between community participatory $\mathrm{M} \& \mathrm{E}$ and project sustainability.

Lastly the study concludes that community participatory $M \& E$ have a significant positive influence on project sustainability.

Basing on the findings, and the conclusions above, project stakeholders' participation should continuously be enhanced to ensure sustainability of the project. Community members should be greatly involved in $M \& E$ activities in each and every stage of project lifecycle for successful project sustainability.

The study also recommends commitment by the community members during their participation in project activities in order to get acquainted with all the information regarding the project so that they are able to successfully take over once the project is completed to ensure its progress and sustainability.

\section{Suggestions for further Study}


Basing on research findings, the researcher would like to recommend to the future researcher to conduct studies in the related field specifically on:

- To examine the contribution of traditional methods of M\&E on project sustainability in Huye District, Rwanda.

- To find out the role of local practical knowledge of $\mathrm{M} \& \mathrm{E}$ on savings for transformationproject success in Huye District, Rwanda

- To assess the effect of participatory approach in $\mathrm{M} \& \mathrm{E}$ on performance of savings for transformationprojects in Huye District, Rwanda.

\section{Acknowledgments}

I firstly appreciate God for guidance; love and humility that have made me reach to the compilation of this study expecting to complete it with more energy and strength. Thanks also go to Dr. Hesbon, O. ANDALA $(\mathrm{PhD})$ who dedicated his time, gave guidance and valuable input in this research study. Many thanks to the lecturers at Mount Kenya University for taking me through the courses of the masters programme of $\mathrm{M} \& \mathrm{E}$ that enriched this and without which the successful study completion would not have been possible. Special regards to World Vision Rwanda and the community members of Mbazi sector for giving me an opportunity to work in savings for transformation project and allow me carry out the research study in therein. I too thank my friends and family for the effort made towards my studies and compilation of this work.

\section{Reference}

1. Ahola J. (2014). Analysis of Influence of Monitoring and and Evaluation practices on Sustainability of Projects.International Journal of Project Management, $\underline{\text { 32(8) }), 1321-1332}$

2. Al Gore, K. (2007). Community Participatory Monitoring and Evaluation. Private Sector Empowerement. World Development. Ohio: Ohio State University.

3. Amin K. (2005). Research Methods:Use of Case Studies, Planning,Conducting and Evaluating Qualitative and Quantitative Research. 4th Edition. Boston: Pearson Education Inc.

4. Barasa F and Jelangat T. (2013). Community Participation in Project Planning, Management and Implementation: Building the Foundation for Sustainable Development. International Journal of Current Research, 5 (2), 398-401.

5. Bartle, R et al. (2007). The nature of Monitoring and Evaluation Definition and purpose.
Retrieved August 26, 2020 http://www.scn.org/cmp/modules/mon-wht.htm

6. Christensen D and Derek H. (2004). Understanding the Role of Vision in Project Success. Success Project Management Journal, 35(3), 11-32.

7. Creswel J. (2012). Educational research: Planning, Conducting and Evaluating Qualitative and Quantitative Research 4thEdution. Boston: Pearson Education Inc.

8. Donaldson S. (2003). Roles for theory in contemporary Evaluation practices: Developing Practical Knowledge, Evaluation Social Programs and Problems, Vision for the new Millenium. 3(3), 111-142.

9. Eduards J. (1993). Sustainable Development in divided World: NGOs and development in a changing world. London: Earth Scam.

10. Edwards $M$ and Hulme D. (2000). Making a difference: NGOs and development in a changing world. London: Earth Scam.

11. ELMT and ELSE. (2014). Final Evaluation of the Enhanced Livelihoods in Mandera Triangle (ELMT) and Enhanced Livelihoods in Southern Ethiopia (ELSE) Program 2009-2011.

12. Gilbert S. (2014). Analyzed the sustainable in project management competencies project. Management Journal, 38:6.

13. Gyrkos T. (2003). Monitoring and Evaluation of Large Scale Helminth Control Project,Acta Tropic. 86(2), 275-282.

14. Hague C. et al. (2003). Participatory planning for sustainable communities. Research report to the Office of The Deputy Prime Minister (ODPM). ODPM, London. Retrieved from http://www.odpm.gov.uk/stellent/groups/odpm_ planning/documents/page/odpm_plan_02 3784.Hcsp on 8th July, 202.

15. Krejcie R et al. (1970). Determining Sample Size for Research Activities. Educational and Psychological Measurement, 606-610.

16. Majid M. (2006). Community Participatory Monitoring and Evaluation the project progress and project Management.

17. Mansuri G and Rao V. (2003). Evaluating Community-Based and Community-Driven Development: A Critical Review of the Evidence." Working paper, Development Research Group. Washington D.C: World Bank. 
18. Marelize G and Kusek J. (2009). Making Monitoring and Evaluation System work, a Capacity Development toolkit. Washington D.C: World Bank.

19. Mugenda O and Mugenda A. (1998). Research methods, Quantitative and Qualitative Approaches. Nairobi: Acts Press.

20. Mulua F. (2008). Participatory Monitoring and Evaluation of Community Projects. Nairobi: Paulines Publications.

21. Musa S. (2002). Feeder Roads and Food Security in Balancing the Load: Women, Gender and Transport. London: Zed Books Ltd.
22. Nabris K. (2002). Monitoring and Evaluation, Civil Society empowerment Jerusalem PASSIA Northern Ghana. World Development.

23. Rao A. (1991). Roles for monitoring and Evaluation practices: Developing Practical Knowledge, Evaluation Social Programs and Problems, Vision for the new Millenium and sustainable development.

24. Tache K and Kimweli R. (2011). Integrated Monitoring and Evaluation flow for sustainability investment project.

25. Zovoushe K. and Gideon P. (2013). Community Participatory Monitoring and Evaluation the project success and project implementation. 